\title{
The Role of Phytosterols Enriched Foods-A Review
}

\author{
M. Penchala Raju, D G Aravind Babu, B Rakesh kumar and C H Rajashekar \\ Department of Food Technology, College of Food Science and Technology Acharya N.G.Ranga Agricultural \\ university, Hyderabad-516390
}

\begin{abstract}
Phytosterols exist as naturally occurring plant sterols that are present in the nonsaponifiable fraction of plant oils. Phytosterols (plant sterols and stanols) are well known for their low density lipoproteincholesterol (LDL-C)-lowering effect. Although many studies have been conducted to resolve the mechanisms of action by which phytosterols lower serum cholesterol. Dietary Phytosterols appear to play an important role in the regulation of oxidation and serum lipids and exhibit anticancer properties. However, as the study confines to the effect of phytosterol on lipid regulation, the review is confined to phytosterol and their role in control of cardiovascular disease (CVD). The information reviewed is presented under the following sections as types of Phytosterols and their structures, mechanism of action, phytosterols in foods for cvd risk reduction, phytosterols as ingredient in functional foods, stability of phytosterols in foods, safety aspects and regulatory status of phytosterols, phytosterols content in foods and phytosterol enriched products are reviewed.
\end{abstract}

Key words: Phytosterols, LDL-Cholesterol

\section{Introduction:}

Phytosterols are plant derived compounds structurally related to mammalian cell- delivered cholesterol that functions as essential constituents of plant cell membranes (Lichtenstein, 2002). Berger et al. (2004) reported that the phytosterols can be divided into two distinct classes, the sterols and stanols, with sterols being the predominant form found in nature. Both classes of phytosterol are naturally occurring and can be found in a variety of foods, including nuts, vegetables oils, seeds and cereals.

\section{Types Of Phytosterols:}

Sterols: $\Delta 5$-Phytosterols found in Sitosterol, Campesterol, Stigmasterol

Stanols: 5 - $\alpha$-Reduced Sterols (From Soy or Wood)

Examples: Sitostanol, Campestanol (Berger et al. 2004).

Phytosterols exist as naturally occurring plant sterols that are present in the nonsaponifiable fraction of plant oils. Structurally, phytosterols are similar to cholesterol except for substitutions on the sterol side chain at the C24 position. Phytosterols are not synthesized in humans, are poorly absorbed, and are excreted faster from the liver than cholesterol, which explains their low presence in human tissues. The primary phytosterols in the diet are sitosterol, stigmasterol, and campesterol. Typical consumption of plant sterols in diet approximately 200400mg/day (Aparna Kuna et al.2011). Aparna Kuna and Poshadri, (2011) reported that phytosterols occurring in free and esterified forms are present ubiquitously in the unsaponifiable fraction of the extractives of most plants. The ester moiety could be fatty acid, ferulic acid or sugar acid. In edible plants, these unsaponifiables are consumed routinely as a part of the human diet. Wong, (2008) reported that appreciable quantities of phytosterols were identified in selected grain processing residues. Preliminary testing of selected samples showed the concentration was found to vary from 1.6 grams per $\mathrm{kg}$ of durum wheat bran to 5.7 grams per $\mathrm{kg}$ in spring wheat germ. Samples of selected grain processing residues were analyzed for phytosterols with the goal of developing a new source of phytosterols for nutritional health-food purposes. The samples studied were distillers' grain, brewers' grain, wheat bran, corn germ and wheat germ. Distillers' grain was considered to be a commercially interesting source of phytosterols and corn germ was considered to be a practical source of phytosterols.The structural similarity between phytosterols and mammalian cholesterol is striking; they mainly differ by a methyl or an ethyl group at the C-24 position in the side chain (Figure .1) Most phytosterols as well as cholesterol have a double bond between C-5 and C-6 in the tetracyclic ring system and thus are called $\Delta^{5}$ sterols. Another group of common phytosterols are $\Delta^{7}$-sterols, with a double bond between C-7 and C-8, and $\Delta^{5}$, 22-sterols with double bonds between C-5 and C-6 and also between C-22 and C-23. Saturated phytosterols with no double bonds in their structure are called phytostanols. The main phytosterol encountered in higher plants is sitosterol. It is often accompanied by its 22-dehydroanalog, stigmasterol. Campesterol also occurs widely in plants (Moreau et al., 2002) (Figure .2).

Figure 1: Structures of common phytosterols, phytostanols, and cholesterol (Moss, 1989).

The principal phytosterols in grain processing residue samples tested were campesterol, campstanol, stigmasterol, sitosterol and sitostanol. 
Figure. 2 illustrates the basic structure of these major sterols. It may be noted that brassicasterol occurs only in Brassica spp. plant materials such as mustard oil and rapeseed oil.

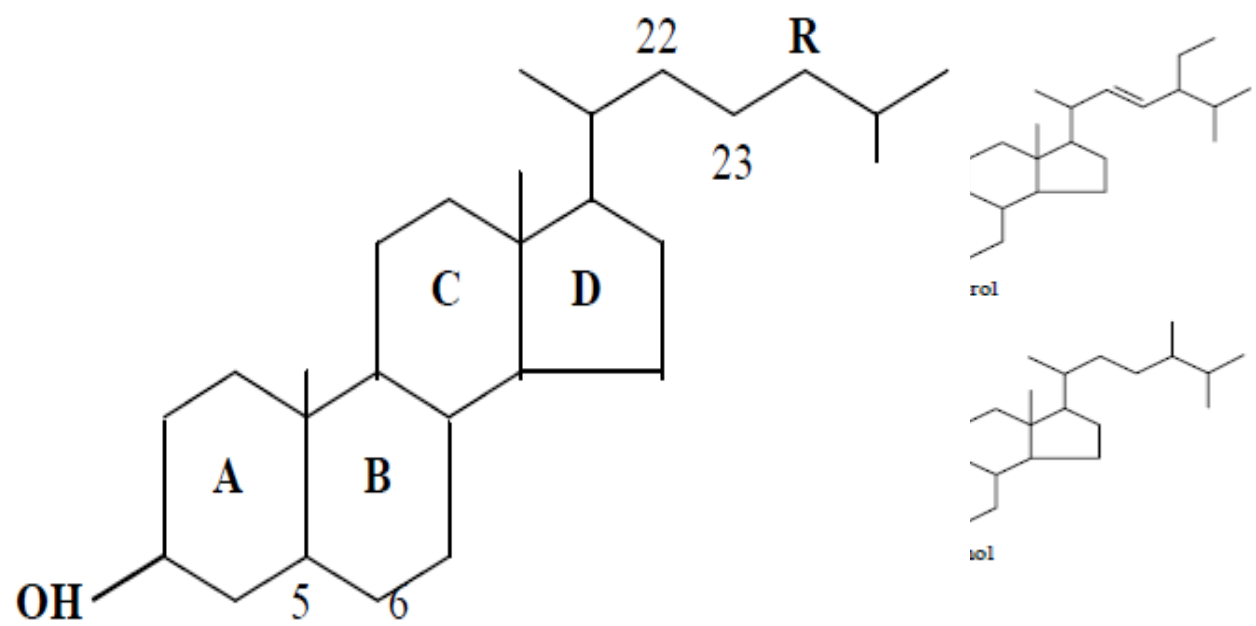

Figure 2: Chemical structure of major phytosterols found in most plant materials.

Source: Wong (2008).

\begin{tabular}{|l|l|l|}
\hline & $\Delta$ & $R$ \\
\hline Brassicasterol & 5,$6 ; 22,23$ & CH3 \\
\hline Campesterol & 5,6 & CH3 \\
\hline Campestanol & Nil & CH3 \\
\hline Stigmasterol & 5,$6 ; 22,23$ & C2H5 \\
\hline Sitosterol & 5,6 & C2H5 \\
\hline Sitostanol & nil & C2H5 \\
\hline
\end{tabular}

\section{Mechanism Of Action:}

The exact mechanism by which phytosterols decrease serum cholesterol levels is not completely understood, but several theories have been proposed. One of them suggests that cholesterol in the intestine, already marginally soluble, is precipitated into a non-absorbable state in the presence of added phytosterols and stanols. Another theory is based on the fact that cholesterol must enter bile-salt and phospholipid-containing 'mixed micelles' in order to pass through intestinal cells and to be absorbed into the bloodstream. Moreover, phytosterols may modulate the action of key transporters involved in cholesterol absorption. Cholesterol absorption is a very important physiological mechanism that regulates cholesterol metabolism (Rozner and Garti, 2006). Phytosterol have been shown to inhibit the uptake of both dietary and endogenously produced (biliary) cholesterol from intestinal cells. Such inhibition results in a decrease in serum total and LDLcholesterol levels. Levels of HDL-cholesterol and triglycerides do not appear to be affected by dietary phytosterol consumption (AbuMweis et al., 2008). A recent trial showed that efficacy of phytosterols is not influenced by dietary cholesterol intake in hypercholesterolemic individuals. Both dietary cholesterol and recirculating biliary cholesterol mix in the intestine and are partially absorbed. Failure to reabsorb intestinal cholesterol is the principal means of cholesterol elimination from the body (kassis et al., 2008). Although many studies have been conducted to resolve the mechanisms of action by which phytosterols lower serum cholesterol, the molecular actions are not fully understood. The main physiological response to ingestion of phytosterols is known to be reduced intestinal absorption of both dietary and endogenously produced cholesterol without, however, any decrease in the levels of high-density lipoprotein (HDL) -cholesterol or triglycerides (Moreau et al., 2002, Ostlund et al., 2002). This interference with absorption is probably related to the similarity in the chemical structures of phytosterols, stanols, and cholesterol (Salo et al., 2002; Plat and Mensink, 2005). Current studies focus on the effects of phytosterols at the epithelial cell level, suggesting that there is an additional longer-lasting process in which phytosterols and stanols actively influence cellular cholesterol metabolism within intestinal enterocytes (Normen et al., 2004; Plat and Mensink, 2005; Thompson and Grundy, 2005). In enterocytes, phytosterols and stanols potentially increase the expression of $A B C$ (adenosine triphosphate (ATP) binding cassette) transporters, integral membrane proteins that use the energy generated from ATP hydrolysis for transportation of a substrate across the membrane. Of these, ABCG5, ABCG8, and 
probably ABCA1 are identified as specific sterol transporters. When dietary phytosterols or stanols enter the enterocytes via micellar transport, they are assumed to be directly transported back to the intestinal lumen by the ABCG5-ABCG8 complex, thus keeping their absorption low. This complex, stimulated by phytosterols and stanols, may also promote the efflux of cholesterol, thereby regulating the total sterol absorption (Schmitz et al., 2001).The suggestion of the incorporation of the ABCG5-ABCG8 complex in transport of phytosterols and stanols is based on the finding that in phytosterolemia (or sitosterolemia, a rare human genetic disorder affecting phytosterol metabolism) the high absorption of phytosterols was due to the deficiency of these transporters (Schmitz et al., 2001; Yu et al., 2002; Gylling and Miettinen, 2005). However, other transporters are also thought to participate in sterol absorption mechanisms, a recent finding being the Niemann-Pick C1-Like 1 transporter (von Bergmann et al., 2005; Gylling and Miettinen, 2005). Mechanisms by which phytosterols and stanols affect cholesterol transportation over the enterocyte membrane are still largely open and why phytosterols are taken up by the enterocytes and then resecreted back into the intestine remains an open question (Von Bergmann et al., 2005). The above-mentioned theory is supported by a recent study showing that mixed micelles enriched with sitostanol or with cholesterol and sitostanol increased intestinal expression of ABCA1 in Caco- 2 cells (Plat and Mensink, 2002). In subsequent animal studies, metabolites of phytosterols have been observed to activate liver $\mathrm{X}$ receptors, which, in turn, activate the expression of ABCG5 and ABCG8 transporters. However, the metabolic conversion of dietary phytosterols has not been elucidated (Kaneko et al., 2003). The potentially important role of ABCG5 and ABCG8 transporters in sterol trafficking has also been tested by disrupting Abcg5 and Abcg8 in mice. This led to a 30-fold increase in serum sitosterol and extremely low biliary cholesterol concentrations ( $\mathrm{Yu}$ et al., 2002). The mechanism of action is summarised in Figure .3 (Quiłlez et al., 2003)

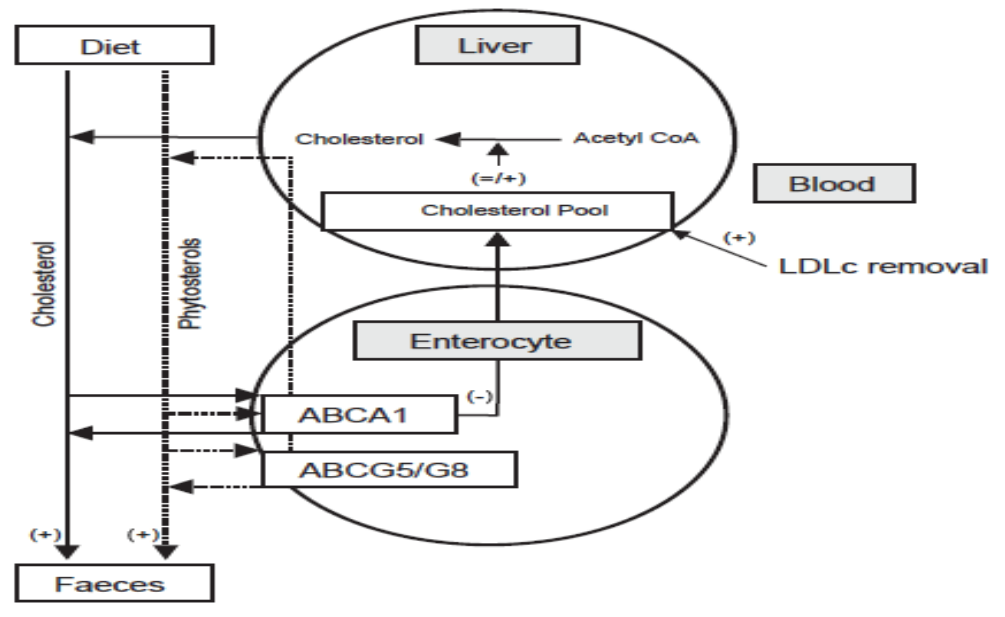

Figure.3: Simplified model of the mechanism of action of phytosterols. Signs in parentheses indicate the effect of phytosterol consumption. Diet plus biliary cholesterol is absorbed approximately by $50 \%$, and phytosterols between $0.1 \%$ and $5 \%$ in enterocytes mediated by $\mathrm{ABC}$ transporters, and the rest is eliminated by faeces. Phytosterol intake in significative quantities reduces the rate of cholesterol absorption and the liver cholesterol pool is diminished. This might determine the upregulation of cholesterol biosynthesis and plasma LDLcholestrol removal. Signs in parentheses indicate the effect of phytosterols consumption (Quiłlez et al., 2003).

\section{Phytosterols In Foods For Cvd Risk Reduction:}

The use of phytostanols for serum cholesterol-lowering purposes in humans was studied by Heinemann et al. (1986). They administered sitostanol at a dose of $1.5 \mathrm{~g} / \mathrm{d}$ for 4 weeks to 6 patients with hypercholesterolemia and observed that total Cholesterol was reduced by 10 per cent and 15 per cent after 3 and 4 weeks, respectively.

Christiansen et al. (2001) demonstrated the efficacy of microcrystalline free phytosterols; serum total and LDLcholesterol levels were reduced by 7.5-11.6 per cent by consuming phytosterol-enriched margarine (1.5 or $3.0 \mathrm{~g}$ of phytosterols per day) during a 6-week run-in and a 6-month experimental period.

\section{Phytosterols As Ingredient In Functional Foods:}

Clifton et al. (2004) demonstrated that phytosterol in all food forms tested for lower serum LDL cholesterol, with low-fat milk being the most effective vehicle with a 16 per cent lowering with $1.6 \mathrm{~g} /$ day of phytosterol. 
Masana et al. (2008) found that plant sterol enriched fermented milk significantly reduced LDL - C and increased the number of moderately hypercholesterolemic patients achieving therapeutic targets.

Dooornbos et al. (2006) showed that phytosterol- enriched fermented milk had significant LDL cholesterol lowering efficacy, when used in either a multiple or single dose drinkable yoghurt, the reductions of LDL - C were in the range of 5 to 10 per cent greater where the phytosterol enriched product were taken along with a meal.

Penchala Raju et al. (2013) studied the effect of phytosterols (PS) enriched flavoured milk on total and LDL (Low density lipoprotein)- cholesterol levels in subjects with hypercholesterolemia and results showed that enrichment of phytosterol in low fat flavoured milk to the experimental group, brought a significant $(\mathrm{p}<0.05)$ reduction of total cholesterol $(2.53 \%)$ and LDL- cholesterol levels $(2.62 \%)$ and concluded that the phytosterolenriched flavoured milk can be used effectively to reduce plasma total and LDL cholesterol levels in hypercholesterolemic individuals and the data suggest that the incorporation of phytosterol enriched flavoured milk into a balanced diet represents a practical dietary strategy in the management of serum cholesterol levels.

Stability at High Temperature:

\section{Stability Of Phytosterols In Foods:}

Phytosterols and their fatty acid esters are quite stable compounds and undergo only limited degradation during oil processing. Only under harsh conditions, such as high temperatures $\left(>1000{ }^{0} \mathrm{C}\right)$ in the presence of oxygen, oxidation of the phytosterol moiety may occur, in the same way as for cholesterol (Soupas, 2006). Phytosterols are mono-unsaturated compounds (double bond in the $\beta$-ring), which are much more stable than the mono-unsaturated fatty acids (e.g. oleic acid), because of steric hindrance by the ring structure. Therefore, even under severe conditions, such as during shallow frying, sterol oxidation products form very slowly (Thanh et al., 2006). Under conditions of use for shallow frying by consumers, (temperatures 160-200 ${ }^{0} \mathrm{C}, 5-10$ minutes of frying) the level of oxidation of sitosterol esters remains below $1.3 \%$. When the matrix consists of liquid oil or liquid margarine and if free sterols are present then these levels are somewhat higher at $2.5 \%$ and 5.1\%, respectively (Salta et al., 2008 and Soupas et a1., 2005). Factors affecting phytosterol oxidation include not only temperature and heating time, but also the composition of the lipid matrix. Since Indian dairy products such as dahi, misti dahi, paneer, butter milk (chhach/chhaas), lassi, etc are processed below $100^{\circ} \mathrm{C}$, it is best to opt for such dairy products as vehicles for phytosterols fortification as compared to other vehicles which involves high temperature processing. ( Aparna and Poshadri, 2012).

\section{Stability during product manufacturing and storage:}

Phytosterols and phytostanols are microbiologically inert as shown by the absence of an effect during the fermentation process used to produce yoghurt (Monu et al., 2008). Furthermore, the ester added to various food products show excellent stability at different $\mathrm{pH}$ values during long term storage (up to at least a year). Phytostanol and phytosterol esters are also stable in milk and fermented milk and products with viable bacteria like yoghurts and yoghurt drinks (Cantrill and Kawamura, 2008).

\section{Oxidative Stability of Phytosterols in Foods:}

The oxidative stability of phytosterols and stanols, i.e. their resistance to oxidation and thus to the formation of oxidation products, needs to be investigated. In terms of stability, the oxidative stability, indeed, is of major concern, since sterols, as unsaturated lipid compounds (steroid alcohols), are susceptible to oxidation (Dutta, 2004).

In a review of genotoxicity of heat-processed foods, oxidized phytosterols were classified as cooked food mutagens, along with acrylamides, heterocyclic amines, nitrosoamines, and polyaromatic hydrocarbons (Jagerstad and Skog, 2005). Research on oxidation of phytosterols has not been as systematic and extensive as with cholesterol, but based on all information available, phytosterols seem to oxidize in a similar fashion to cholesterol. This can also be assumed from their structural similarities (Dutta, 2004). A foundation for understanding sterol oxidation mechanisms has been provided by studies conducted on fatty acid oxidation (Lercker and Rodriguez-Estrada, 2002). Sterol oxidation can proceed via nonenzymic or enzymic pathways (Dutta, 2004). Nonenzymic pathways can further be divided into oxidation by a free radical mechanism, i.e. autoxidation, or oxidation by a nonradical mechanism, i.e. photoxidation (Lercker and Rodriguez- Estrada, 2002).

\section{Safety Aspects And Regulatory Status Of Phytosterols:}

Phytosterols have been used for lowering plasma cholesterol levels for half a century now, and so far, no marked adverse effects have been reported (Ling and Jones, 1995; Berger et al., 2004; Kritchevsky, 2004; Gylling and Miettinen, 2005; Kritchevsky and Chen, 2005; Plat and Mensink, 2005; Salo et al. 2005; Penchala raju et al. 2013). FDA has granted GRAS status for many phytosterol/stanol ingredients (FDA, 2000a), and SCF 
in the EU has thoroughly reviewed the safety of phytosterols, phytostanols, and their esters and sanctioned them for use in a variety of foods (SCF, 2000; 2003a, b,c). Noteworthy, however, is that there is no experience of the effects of long-term consumption of phytosterols and stanols as part of the daily diet. This leaves open the possibility of unsuspected effects (Katan et al., 2003; St-Onge and Jones, 2003). Promotion for the use of plant sterols for LDL-C lowering is increasing, but prudence dictates that the dose of phytosterols should not exceed $2 \mathrm{~g}$ / day. An additional concern of uncertain significance is the interference with the absorption of certain fat soluble vitamins (Katan et al., 2003, Devaraj et al., 2006).

Recent studies of plant sterol and stanol esters in humans have shown; however, that maximum cholesterollowering benefit is achieved at doses of 2-3 g per day (Hallikainen et al., 2000; Jones et al., 2000; Maki et al., 2001).

\section{Phytosterols Content In Foods:}

In general, the main sources of phytosterols in the human diet are vegetable oils, vegetable oil based food products, cereal grains, cereal-based foods, and nuts. According to a recent study in Finland, cereal and cereal products, especially rye, were the major sources for phytosterols, followed by margarine (Valsta et al., 2004). Phytosterol content of crude vegetable oils lies between 70 and $1100 \mathrm{mg} / 100 \mathrm{~g}$ of oil, with rapeseed and corn oils being the richest sources, and olive and palm oils the poorest (Piironen and Lampi, 2004). Some special oils, like rice bran oil and wheat germ oil, can contain phytosterols in amounts up to $3200 \mathrm{mg} / 100 \mathrm{~g}$ of oil (Piironen et al., 2000). The most unique oil seems to be corn fiber oil, which contains phytosterols in quantities of about $10,000 \mathrm{mg} / 100 \mathrm{~g}$ of oil (Moreau et al., 2002). Among cereals, the richest sources of phytosterols are corn $(65-120 \mathrm{mg} / 100 \mathrm{~g})$ and rye $(70-110 \mathrm{mg} / 100 \mathrm{~g})$, while wheat, barley, and oats contain 35-80 $\mathrm{mg} / 100 \mathrm{~g}$ (Piironen and Lampi, 2004). Different nuts contain phytosterols in the range of 30-220 mg/100 g (Piironen et al., 2000).

Despite their high moisture content, the contribution of vegetables, fruits, and berries in phytosterols intake has also been shown to be significant (Piironen et al., 2003; Valsta et al., 2004). On a fresh weight basis, phytosterol contents of fresh vegetables range from 5 to $40 \mathrm{mg} / 100 \mathrm{~g}$, the highest contents measured in broccoli, Brussels sprouts, cauliflower, and dill. In fresh fruits, phytosterols contents lie within the range of 10-20 mg/100 $\mathrm{g}$ fresh weight, and in fresh berries $6-30 \mathrm{mg} / 100 \mathrm{~g}$ fresh weight. Wild berries, like lingonberry and blueberry, are more phytosterol-rich than cultivated berries such as blackcurrant, redcurrant, and strawberry (Piironen et al., 2003).

\section{Phytosterol Enriched Products For The Control Of Ldl Cholesterol:}

A study showed that low fat dairy based food products like milk and yoghurt enriched with plant sterol esters, were similarly effective in lowering total cholesterol (TC) and LDL- cholesterol concentrations as fat based foods like spreads and margarine (Noakes et al., 2005; Hallikainen et al., 2000). A study investigated the effect of phytosterols added into milk on plasma concentrations of total cholesterol, high-density lipoprotein cholesterol (HDL-C), and LDL-C, and on biochemical, hematologic, and hemorheological profiles in healthy and hypercholesterolemic subjects in Portugal. The results obtained in this study indicate that phytosterolenriched milk is a good vehicle for reducing plasma cholesterol in hypercholesterolemic subjects (Goncalves $e t$ al., 2007).Elevated plasma total cholesterol (TC) 5 and LDL-cholesterol (LDL-C) are a major risk factor for coronary heart disease (CHD). Phytosterols (plant sterols and stanols) are among the dietary options available to lower elevated plasma TC and LDL-C concentrations. The cholesterol-lowering properties of phytosterols were observed in humans already in the early 1950s (Salo et al. 2005). Since then, a vast number of human trials have shown that phytosterols, mainly in the form of plant sterols or stanols esterified to vegetable oil fatty acids (mainly C18), significantly lower TC and LDL-C when incorporated into various food products (Aparna et al., 2011). Dietary Phytosterols appear to play an important role in the regulation of oxidation and serum lipids and exhibit anticancer properties (Peter et al., 2009). Demonty et al. (2010) reported that the recommended intake of $2 \mathrm{~g} / \mathrm{d}$, the expected LDL-C lowering effect of phytosterols was 9 percent. A reduction in LDL-Cholesterol of $10 \%$ would reduce the incidence of coronary heart disease by 10-20 percent (Demonty et al., 2010).

Table 1: Total phytosterols contents of selected foods

\begin{tabular}{|c|c|c|}
\hline S.No & Phytosterol food sources & $\begin{array}{l}\text { Total phytosterols content } \\
(\mathrm{mg} / 100 \mathrm{~g})\end{array}$ \\
\hline \multicolumn{3}{|c|}{ OILS } \\
\hline 1 & Rice bran & 1055 \\
\hline 2 & Corn & 952 \\
\hline 3 & Wheat germ & 553 \\
\hline 4 & Flax seed & 338 \\
\hline
\end{tabular}


The Role Of Phytosterols Enriched Foods-A Review

\begin{tabular}{|c|c|c|}
\hline 5 & Cottonseed & 327 \\
\hline 6 & Soybean & 221 \\
\hline 7 & Peanut & 206 \\
\hline 8 & Olive & 176 \\
\hline 9 & Coconut & 91 \\
\hline 10 & Palm & 49 \\
\hline \multicolumn{3}{|c|}{ Vegetables } \\
\hline 11 & Beet root & 25 \\
\hline 12 & Brussels sprout & 24 \\
\hline 13 & Cauliflower & 18 \\
\hline 14 & Onion & 15 \\
\hline 15 & Carrot & 12 \\
\hline 16 & Cabbage & 11 \\
\hline 17 & Yam & 10 \\
\hline \multicolumn{3}{|c|}{ Fruits } \\
\hline 18 & Orange & 24 \\
\hline 19 & Banana & 16 \\
\hline 20 & Apple & 12 \\
\hline 21 & Cherry & 12 \\
\hline 22 & Peach & 10 \\
\hline 23 & Pear & 8 \\
\hline \multicolumn{3}{|c|}{ Nuts } \\
\hline 24 & Cashew & 158 \\
\hline 25 & Almond & 143 \\
\hline 26 & Pecan & 108 \\
\hline 27 & Pistachio & 108 \\
\hline 28 & Walnut & 108 \\
\hline \multicolumn{3}{|c|}{ Legumes } \\
\hline 29 & Pea & 135 \\
\hline 30 & Kidney bean & 127 \\
\hline 31 & Broad bean & 124 \\
\hline
\end{tabular}

Source: Aparna et al., (2011).

\section{Conclusion:}

Phytosterols have gained a prominent position in strategies to lower CVD risk because of their serum LDLCholesterol lowering effects and it is evident from the foregoing discussion that a phytosterol- enriched products can be used effectively to reduce plasma total and LDL cholesterol levels in hypercholesterolemic individuals and the data suggest that the incorporation of phytosterol enriched products into a balanced diet represents a practical dietary strategy in the management of serum cholesterol levels. Although no direct evidence is available yet for the ability of phytosterols to lower coronary heart disease incidence, the well documented cholesterol lowering effect of phytosterols is the basis for recommendations to include phytosterols into strategies to lower LDL-C concentration. The cholesterol lowering potential of phytosterols may thus depend upon previous dispersion into a fat matrix and on the physical nature of the food. 


\section{References:}

[1]. AbuMweis, S.S., Barake, R and Jones, P. 2008. Plant sterols/stanols as cholesterol lowering agents: a meta-analysis of randomized controlled trials. Food and Nutrition Research. 52-56.

[2]. Aparna Kuna and Poshadri, A. 2012. Phytosterol- A functional ingredient for indian food industry. Indian Food Industry.30(3):21-28.

[3]. Aparna Kuna., Narendar Raju, P and Poshadri, A. 2011. Phytosterols as functional ingredients for dairy foods. Indian journal of dairy sciences. 64 (5): 359-367.

[4]. Berger, A., Jones, P.J.H and Abumweis, S.S. 2004. Plant sterols: factors affecting their efficacy and safety as functional food ingredients. Lipids in Health and Disease 3:5.http://www.lipidworld.com/content/3/1/5.

[5]. Cantrill, R and Kawamura, Y. 2008. Phytosterols, phytostanols and their esters, chemical and technical assessments. Proceedings of $69^{\text {th }}$ JEFCA, 1- 13 .

[6]. Christiansen, L.I., Lahteenmaki, P.L.A., Mannelin, M.R., Seppanen-Laakso, T.E., Hiltunen, $\quad$ R.V.K and Yliruusi, J.K. 2001. Cholesterol-lowering effect of spreads enriched with microcrystalline plant sterols in hypercholesterolemic subjects. European Journal of Nutrition. 40: 66-73.

[7]. Clifton, P.M., Noakes, M., Sullivan, D., Erichsen, N., Ross, D., Annison, G., Fassoulakis, A and Cehun, M. 2004. Cholesterollowering effects of plant sterol esters differ in milk, yoghurt, bread and cereal. European Journal of Clinical Nutrition. 58: $503-509$

[8]. Demonty, I., Ras, T.R., Henk, C.M., knaap, V.D., Duchateau, S.M.J.E., Meijer, L., Zock, P.L., Geleijnse, J.M and Trautwen, A.E. 2010. Continuous dose-response relationship of the LDL-cholesterol-lowering effect of phtosterol intake. Journal of nutrition. 271-284.

[9]. Devaraj, S., Jialal, I and Vega-Lopez, S. 2006. Plant Sterol-Fortified Orange Juice Effectively Lowers Cholesterol Levels in Mildly Hypercholesterolemic Healthy Individuals. Arteriosclerosis, Thrombosis and Vascular Biology. 24: 25-28.

[10]. Doornbos, A.M., Meynen, E.M., Duchateau, G.S., van der Knaap, H.C., and Trautwein, E.A. 2006. Intake occasion affects the serum cholesterol lowering of a plant sterol-enriched single-dose yoghurt drink in mildly hypercholesterolaemic subjects. European Journal of Clinical Nutrition. 60:325-333.

[11]. Dutta, P.C and Appelqvist, L.A. 1996. Sterols and Sterol Oxides in the potato products, and Sterols in the vegetable oils used for industrial frying operations. Grasas Aceites. 47: 38-47.

[12]. Dutta, P.C. 2004. Chemistry, analysis, and occurrence of phytosterol oxidation products in foods. In:Phytosterols as Functional Food Components and Nutraceuticals, P.C. Dutta (ed.). 397-417.

[13]. FDA (US Food and Drug Administration). 2000a. Agency response letter GRAS notice no. 000039. www.cfsan.fda.gov.

[14]. Gersh, B.J., Sliwa, K and Mayosi, B.M. 2010. Novel therapeutic concepts: the epidemic of cardiovascular disease in the developing world: global implications. European Heart Journal. 31: 642-648.

[15]. Goncalves, S., Vasco Maria, A., Silva, A.S., Martins-Silva, J., and Saldanha, C. 2007. Milk enriched with phytosterols reduces plasma cholesterol levels in healthy and hypercholesterolemic subjects. Nutrition Research. 27: 200-205.

[16]. Gylling, $\mathrm{H}$ and Miettinen, T.A. 2005. The effect of plant stanol- and sterol-enriched foods on lipid metabolism, serum lipids and coronary heart disease. Journal ofAnnals of Clinical Biochemistry. 42: 254-263.

[17]. Gylling, $\mathrm{H}$ and Miettinen, T.A. 2005. The effect of plant stanol- and sterol-enriched foods on lipid metabolism, serum lipids and coronary heart disease. Journal of Annals of Clinical Biochemistry. 42: 254-263.

[18]. Hallikainen M.A., Sarkkinen, E.S and Uusitupa, M.I.J. 2000. Plant stanol eaters affect serum cholesterol concentrations of hypercholesterolemic men and women in a dose dependent manner. Journal of Nutrition. 130(4): 767-776.

[19]. Heinemann, T., Leiss, O and von Bergmann, K. 1986. Effect of low-dose sitostanol on serum cholesterol in patients with hypercholesterolemia. Atherosclerosis. 61: 219-223.

[20]. Jagerstad, M. and Skog, K. 2005. Genotoxicity of heat-processed foods. Mutation Research. 574: 156-172

[21]. Jones P.J., Raeini-Sarjaz, M and Ntanios, F.Y. 2000. Modulation of plasma lipid levels and cholesterol kinetics by phytosterol versus phytostanol esters.Journal of Lipid Research. 41(5): 697-705.

[22]. Jones, P.J.H and Catherine, A., Vanstone, C.A., Sarjaz., M.R and St-Onge, M.P. 2003. Phytosterols in low- and nonfat beverages as part of a controlled diet fail to lower plasma lipid levels. Journal of Lipid Research. 44: 1713-1719.

[23]. Kaneko, E., Matsuda, M., Yamada, Y., Tachibana, Y., Shimomura, I. and Makishima, M. 2003. Induction of intestinal ATPbinding cassette transporters by a phytosterols derived liver X receptor agonist.Journal of Biological Chemistry. 278: 3609136098 .

[24]. Kassis, A.N., Vanstone, C.A., AbuMweis, S.S and Jones, P.J.H. 2008. Efficacy of plant sterol is not influenced by dietary cholesterol intake in hypercholesterolemic individuals. Metabolism. 57: 339-346.

[25]. Katan, M.B., Grundy, S.M., Jones, P., Law, M., Miettinen, T and Paoletti, R. 2003. Efficacy and safety of plant stanols and sterols in the management of blood cholesterol levels. Mayo Clinic Proceedings. 78: 965-978.

[26]. Kritchevsky, D and Chen, S.C. 2005. Phytosterols - health benefits and potential concerns: a review. NutritionResearch. 25: 413428.

[27]. Kritchevsky, D. 2004. Safety of phytosterols and phytosterol esters as functional food components. In P.C. Dutta (ed.) Phytosterols as Functional Food Components and Neutraceuticals, Marcel Dekker Inc., New York. 347-363.

[28]. Lercker, G and Rodriguez-Estrada, M.T. 2002. Cholesterol oxidation mechanisms. In: Cholesterol and Phytosterol Oxidation Products, F. Guardiola, P.C. Dutta, R. Codony and G.P. Savage (eds.), AOCS Press, Champaign, Illinois. 1-25.

[29]. $\quad$ Lichtenstein, A.H. 2002. Plant sterols and blood lipid levels. Current opinion in clinical nutrition and metabolic care. 5: 147152.

[30]. Ling, W.H and Jones, P.J.H. 1995. Dietary phytosterols: a review of metabolism, benefits and side effects. Journal of Life Sciences. 57: 195-206

[31]. Maki, K.C., Davidson, M.H and Umporowicz, D.M. 2001. Lipid responses to plant-sterolenriched reduced-fat spreads incorporated into a National Cholesterol Education Program Step I diet. American Journal of Clinical Nutrition. 74(1): 33-43.

[32]. Masana, L., Nicolle, C., Camps, J., and Villoria, J. (2008). Plant sterol-enriched fermented milk enhances the attainment of LDLcholesterol goal in hypercholesterolemic subjects. European Journal of Nutrition. 47:32-39.

[33]. Monu, E., Blank, G., Holley, R and Zawistowski, J. 2008. Phytosterol effects on milk and yoghurt microflora. Journal of food science. 1-6.

[34]. Moreau, R.A., Whitaker, B.D and Hicks, K.B. 2002. Phytosterols, phytostanols, and their conjugates in foods: structural diversity, quantitative analysis, and health-promoting uses. Progress in Lipid Research. 41: 457-500.

[35]. Moss, G.P. 1989. The nomenclature of steroids: recommendations by the IUPAC- IUB jointcommission on biochemical nomenclature. European Journal of Biochemistry. 186: 429-458. 
[36]. Noakes, M., Clifton, P.M., Doornbos, A.M and Trautwein, E.A. 2005. Plant sterol ester-enriched milk and yoghurt effectively reduce serum cholesterol in modestly hypercholesterolemic subjects. European Journal of Nutrition. 44: 214-222.

[37]. Normen, L., Frohlich, J and Trautwein, E. 2004. Role of plant sterols in cholesterol lowering. In P.C. Dutta (ed.) - Phytosterols as Functional Food Components and Neutraceuticals, Marcel Dekker Inc., New York. 243-315.

[38]. Ostlund, R.E. Jr., McGill, J.B., Zeng, C.M., Covey, D.F., Stearns, J., Stenson, W.F and Spilburg, C.A. 2002. Gastrointestinal absorption and plasma kinetics of soy $\Delta 5$-phytosterols and phytostanols in humans. American Journal of PhysiologyEndocrinology and Metabolism. 282: 911-916.

[39]. Penchala Raju, M., Poshadri, A., Aparna Kuna.2013.Plant sterol-enriched low fat flavoured milk enhances the attainment of LDL cholesterol goal in hypercholesterolemic subjects. International Journal of Engineering Research \& Technology (IJERT).2(11):446-451.

[40]. Peter J.H. Jones and Suhad, S. AbuMweis. 2009. Phytosterols as functional food ingredients: linkages to cardiovascular disease and cancer. Current opinion in clinical nutrition and metabolic care. 12: 1477-151.

[41]. Piironen, V and Lampi, A.M. 2004. Occurrence and levels of phytosterols in foods. In: Phytosterols as Functional Food Componentsand Nutraceuticals. Ed. P. C. Dutta, Marcel Dekker, Inc.,New York (USA). 1-32.

[42]. Piironen, V., Toivo, J., Puupponen-Pimia, R and Lampi, A.M. 2003. Plant sterols in vegetables, fruits and berries. Journal of the Science of Food and Agriculture.83: 330-337.

[43]. Piironen,V., Lindsay, D.G., Miettinen, T.A., Toivo, J and Lampi, A.M. 2000. Plant sterols: biosynthesis, biological function and their importance to human nutrition. JournaloftheScienceofFoodandAgriculture. 80: 939-966.

[44]. Plat, J and Mensink, R.P. 2002. Increased intestinal ABCA $_{1}$ expression contributes to the decrease in cholesterol absorption after plant stanol consumption. Journalof Federation of American Societies for Experimental Biology. 16: 1248-1253.

[45]. Plat, J and Mensink, R.P. 2005. Plant stanol and sterol esters in the control of blood cholesterol levels: mechanism and safety aspects.American Journal of Cardiology.96: 15-22.

[46]. Quilez, J., Garcia-Lorda, P and Salas-Salvado, J. 2003. Potential uses and benefits of phytosterols in diet: present situation and future directions. Journal of Clinical Nutrition. 22(4): 343-351.

[47]. Rozner, S and Garti, N. 2006. The activity and absorption relationship of cholesterol and phytosterols. Colloids and surfaces. A, physicochemical and engineering aspects. 282-435.

[48]. Salo, P., Hopia, A., Ekblom, J., Lahtinen, R. and Laakso P. 2005. Plant stanol ester as a cholesterollowering ingredient of Benecol ${ }^{\circledR}$ foods. In C.A. Akoh and O.M. Lai (eds.)- Healthful Lipids, AOCS Press, Champaign, Illinois. 699-730.

[49]. Salo, P., Wester, I and Hopia, A. 2002. Phytosterols. In F.D. Gunstone (ed.) - Lipids for Functional Foodsand Neutraceuticals, The Oily Press, Bridgwater. 183-224.

[50]. Salta, F.N., Kalogeropoulos, N., Karavanou, N and Andrikopoulos, N.K. 2008. Distribution and retention of phytosterols in frying oils and fried potatoes during deep and pan frying. European Food Research Technology. 41: 391-400.

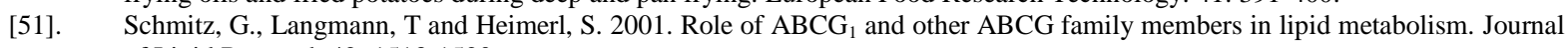
of Lipid Research 42: 1513-1520.

[52]. Soupas, L. 2006. Oxidative stability of phytosterols in food models and foods (Academic dissertation). University of Helsinki. ISBN 952-10-3423-8.

[53]. Soupas, L., Huikko, L., Lampi, A.M and Piironen, V. 2005. Esterification affects phytosterol oxidation. European Journal of Lipid Science Technology. 107: 107-118.

[54]. St-Onge, M.P and Jones, P.J.H. 2003. Phytosterols and human lipid metabolism: efficacy, safety, and novel foods. Lipids.38 (4): 367-375.

[55]. Thanh, T.T., Vergnes, M.F., Kaloustian, J., El-Moselhy, T.F., Amiot-Carlin, M.J and Portugal, H. 2006. Effect of storage and heating on phytosterol concentrations in vegetable oils determined by GC/MS. Journal of the Science of Food and Agriculture. 86: $220-225$.

[56]. Thompson, G.R and Grundy, S.M. 2005. History and development of plant sterol and stanol esters for cholesterol-lowering purposes.American Journal of Cardiology. 96: 3-9.

[57]. Valsta, L.M., Lemstrom, A., Ovaskainen, M. L., Lampi, A.M., Toivo, J. Korhonen, T and Piironen V. 2004. Estimation of plant sterol and cholesterol intake in Finland: quality of new values and their effect on intake. British Journal of Nutrition. 92: 671-678.

[58]. Von Bergmann, K., Sudhop, T and Lutjohann, D. 2005. Cholesterol and plant sterol absorption: recent insights. American Journal of Cardiology. 96(suppl.): 10D- 14D.

[59]. WHO. 2009. World Health Organization. World Health Statistics. 2009:114.

[60]. Wong, A. 2008. Phytosterols in selected grain processing residues. Electronic Journal of Environmental, Agricultural and Food Chemistry. 7 (6): 2948-2958.

[61]. Yu, L., Hammer, R.E., Li-Hawkins, J., von Bergmann, K., Lutjohann, D., Cohen, J.C and Hobbs, H.H. 2002. Disruption of Abcg5 and Abcg8 in mice reveals their crucial role in biliary cholesterol secretion. Proceedings of the National Academy of Sciences USA99: 16237-16242. 